\title{
Development and Protection of Geological Resources in Datong Volcanic Cluster National Geopark
}

\author{
Yujie Dong ${ }^{1}$ and Lilei Zhang ${ }^{1,2}$ \\ ${ }^{1}$ College of Architecture and Surveying Engineering, Datong University, 037000 Datong, China \\ ${ }^{2}$ Datong Prevention and Control of Geological Hazards and Recovery of Geological Environment in Mines Key Laboratory, 037000 \\ Datong ,China
}

\begin{abstract}
Volcanic resources are a kind of special tourism resources, with its unique geomorphologic features and geological structure, attracting a large number of tourists for sightseeing and visiting. Based on the development status of Datong Volcanic Cluster National Geopark, this paper analyzes the advantages, disadvantages, opportunities and challenges of the development of Datong Volcanic Cluster National Geopark, and puts forward some suggestions on the development and protection of volcanic Cluster geological resources.
\end{abstract}

\section{Preface}

Up to January 12, 2019, the Chinese government has approved the naming of 213 national geoparks in succession, which is still a rare tourist resource among the large number of tourist attractions in Europe and belongs to relatively scarce tourism resources. Tourism has been recognized by more and more countries as one of the most energy efficient industries, and has also become an important measure for the future economic transformation of many regions and cities. Datong Volcanic Cluster National Geopark is the only volcanic geopark in Datong, shouldering the multiple tasks of developing tourism resources and strengthening the popularization of geological knowledge. So how to promote the orderly, efficient and sustainable development of Datong Volcanic Cluster National Geopark is a realistic problem at present.

\section{Overview of Datong Volcanic Cluster}

The Datong Volcanic Cluster National Geopark, located in Datong county, Datong city, Shanxi Province, With a total area of 129.8 square kilometers. It is divided into three scenic spots: Datong Volcano Cluster, Sanggan River and Tyurin Valley. The eruption occurred during the upper pleistocene Mesozoic, which was roughly divided into three phases, each with multiple eruptions. The existing volcanic cluster consists of more than 30 volcanic cones of different sizes, and at present, there are more than 10 well-developed volcanoes on the surface, including Jinshan, Heishan, Langwoshan, Xiaoniutoushan, Gelaoshan, Shuangshan, Huashan, Pai Loushan, Haotiansishan, which is the largest, best preserved and richest intraplate rift volcanic cluster in north China, and the only one developed on the loess plateau in the world. The park was qualified for construction in August 2009, then was named by the Ministry of Land and Resources in the same year in December and officially opened in August 2014.

Lithology of Datong Volcanic Cluster is mainly alkaline olivine basalt series, and part of it is the early middle pleistocene basalts group tholeiitic basalt ${ }^{[1]}$, while the volcanic cone is mainly lava and stratified cones composed of pyroclastic tephra, and the volcanoes form mainly includes cone, horseshoe-shaped, shield, ridge hillock, etc., as well as a small amount of tire volcano. According to the classification system of Classification, Investigation and Evaluation of Tourism Resources, the tourism resources of Datong Volcanic Cluster can be classified into 8 major categories and 31 sub-categories. In addition to volcanic clusters and other familiar geological tourism resources, there are Wulong gorge, Sanggan River, Earth Forest, fault, subsidence basin, rock profile, ancient activity sites and other tourism resources.

\section{SWOT analysis of Datong Volcano Cluster Tourism Resources}

SWOT analysis method, also known as situation analysis method, has been widely concerned since it was proposed in the 1980s, and has been widely used in the field of tourism research in recent years. This paper intends to use SWOT analysis method to conduct qualitative analysis on the development of Datong Volcanic Cluster geological resources to provide suggestions and opinions for the later development of the park.

\subsection{Advantages}

\subsubsection{Scarcity of Resources}


Datong Volcanic Cluster is the intraplate volcanic group of rift system in north China with the largest scale, best preservation and most varied content, which is the only volcanic cluster in the world that develops on the loess plateau. There are a large number of volcanoes in the geopark, and the faults, geological profiles, pre-volcanic landforms and the weathering and denudation relics in the later stage are well preserved, which are very scarce geological resources in Datong and even the surrounding areas.

\subsubsection{Abundant Tourism Resources}

In addition to the volcanic cluster, there are many tourist resources in Datong Volcanic Cluster National Geopark, such as Wulong gorge, Sanggan River, Earth Forest, fault, subsidence basin, rock profile, temples, tombs, famous people's former homes, etc., which are of great value both from the perspective of geological investigation and natural sightseeing.

\subsubsection{Convenient Regional Transportation}

Datong Volcanic Cluster National Geopark, located in Datong city east in Datong county, is 28 kilometer away from the Datong city, 350 kilometers away from Beijing, 300 kilometers away from Taiyuan, and only 10 kilometers from Datong Airport. The railway and highway is more convenient, and the high-speed railway from Datong to Xi'an and Beijing is under construction, which will provide convenience for passengers travel around.

\subsubsection{Suitable Climatic Environment}

Datong Volcanic Cluster, located in the Loess Plateau, belongs to the temperate continental monsoon climate, so the climate is distinct throughout the year (the summer temperature is low and the autumn is dry and sunny), which is a good choice for the surrounding areas to avoid summer heat. Under the construction of multiple projects including the northwest-north-northeast China networks of shelterbelts, Beijing-Tianjin sandstorm control, and returning farmland to forest and grassland, the environment of Datong area has been improved obviously, and "Datong Blue" is quite famous in the surrounding areas.

\subsection{Disadvantages}

\subsubsection{Inadequate Infrastructure and Tourism Development Work}

Datong Volcanic Cluster National Geopark was qualified for construction in August 2009, then was named by the Ministry of Land and Resources in the same year in December and officially opened in August 2014, so its overall development and construction time is short, the development level is low, and no brand effect has been formed. So far, the tourist distribution center within the scenic area, Self-driving car and tour bus parking, basic driving and pedestrian road, pavilion for rest, all kinds of signs and hardening of the greening work have been basically completed, but the corresponding tourist service center, the dining, the accommodation, the interpretation system, and the tourist experience interactive systems are not perfect yet, so the tourists only have a general experience.

\subsubsection{Lack of Regional Coordination}

Although the tourism resources of Datong Volcanic Cluster are relatively rich, most of them are in the state of their own development. Wulong gorge, Earth Forest, Haotian Temple and other scenic spots all sell tickets separately, which are not closely related to each other and lack of regional coordination.

\subsubsection{Low Overall Popularity}

Although Datong Volcanic Cluster is rare in some area, it has a great popularity in the domestic and even international geological workers. But in its own province and among the local people, there is no great popularity, not to mention on the domestic and international influence Most tourists are just heard of Datong Volcanic Cluster, but know nothing about its scientific value and natural scenery, so people's motivation to visit the volcano cluster is not strong.

\subsection{Opportunity}

\subsubsection{Industry Development Prospect}

With the continuous development of national economy, tourism has occupied an increasingly important position in people's daily life, and many famous natural heritages, scenic spots and national parks both at home and abroad are based on geological landscapes, many of which have become the pillar of local tourism. Datong Volcanic Cluster, as the intraplate volcanic group of rift system in north China with the largest scale, best preservation and most varied content, is the only volcanic cluster in the world that develops on the loess plateau. The typical location and geomorphologic features of the volcanic cluster, the well-treated geological profile, the beautiful natural landscape and the cool and suitable climate all have great tourist attractions.

\subsubsection{Policy Development Guarantee}

At the same time, Shanxi is in a critical period of economic development and transformation, and the whole province is vigorously advocating Green Rise. Besides, Datong is also selected as "Provincial Model County of Leisure Agriculture and Rural Routing Tourism", and its good economic policies have also created favorable conditions for the tourism development of Datong Volcanic Cluster National Geopark. What's more, The "Green Development" model of Datong Volcanic Cluster 
National Geopark will also certainly provide some reference for Datong's economic theme.

\subsection{Threat}

\subsubsection{Fewer Tourists}

Datong has fewer foreign tourists, and most visitors are from local or surrounding areas, so the number of tourists is relatively limited. In addition, there are scenic spots such as Yesanpo National Geopark, Wutai Mountain National Geopark, Baishi Mountain National Ggeopark, Xuankong Temple and Yingxian Wooden Pagoda in the surrounding areas, which further lead to the diversion of tourists and the loss of part of the tourism market. At the same time, the decrease of the number of tourists will inevitably lead to the decrease of income, which will also have a certain impact on the daily maintenance and management of the park.

\subsubsection{Conflict between Development and Protection}

In order to develop tourism, we need to plan and develop the whole geopark, but such kind of development will also inevitably have a certain influence on the ecological environment and resource characteristics of the park, making the unity of opposites between development, destruction and protection. Therefore, the manager of Datong Volcanic Cluster National Geopark have to effectively deal with the contradiction between tourism development and geological resource protection, and to find a balance between them.

\section{Development and Protection Ideas of Datong Volcano Cluster}

\subsection{Unified Planning and Rational Layout}

To make the sustainable development of tourism, there must be an overall planning that takes the protection of ecology and other factors into consideration, especially the Datong Volcanic Cluster National Geopark is vast, which except for the volcano cluster that tourists generally know, there are also miraculous $\mathrm{Wu}$ Long Gorge, Earth Forest and other scenic spots, so it is more necessary for the development department to complete the overall plan, ensure the scenic spots are relatively independent but also relative to each other, and at the same time, do a good job in the small transportation, food, tourist distribution center planning to enhance the comfort of tourists. In addition, for most of the current scenic spots, it is very difficult to attract enough tourists just by a single static sightseeing tour project. Therefore, other projects can be appropriately considered in the planning of geoparks to enhance the sense of participation of tourists, such as: the development of walking or cycling programs to meet the needs of the public for outdoor sports; the development of long-distance sightseeing projects such as hot air balloon and airship, so that tourists can observe a complete view of volcano cluster; it can establish contact with surrounding schools such as Datong University to develop related cultural and creative products.

\subsection{Balance the Protection of Geological Landscape and the Development of Tourism Resources}

There is a big difference between the development of geopark tourism resources and other tourism resources, that is, geological resources are non-renewable in a short period of time. Therefore, in the development of resources, we must pay attention to the balance between the development of resources and protection, and have moderate development, as far as possible to develop the tourism resources that do not affect or less affect the environment and geological phenomena. When necessary, the whole geopark can be zoned open to protect the area where geological phenomena are typical and easily destroyed or to limit the tourist flow.

\subsection{Strengthen the Proportion of Scientific Popularization of Geological Knowledge}

In recent years, most researches on Datong Volcanic Cluster are carried out from the perspective of tourism development, while the development of geological resources protection is placed relatively in the rear, but for Datong Volcanic Cluster, the more important is the geological value, especially the value of the unique and well-preserved quaternary volcanic cluster in Datong and its surrounding areas. Therefore, the development of Datong Volcanic Cluster National Geopark needs to highlight the scarcity and uniqueness of geological resources. Since the opening of Datong Volcanic Cluster National Geopark, there have been many ways and means adopted to strengthen the publicity of popular science like the knowledge of volcanoes, but its depth and influence are far from enough. Datong Volcanic Cluster can take the popular science of geological knowledge as the starting point, making cooperation with primary and secondary schools and colleges to explore various popular science learning processes such as the simulation of geological process, the explanation of popular science of geological knowledge, the study of geological profile observation and the geological practice base.

\subsection{Improve Regulations and Management Systems}

Tourism is a kind of low carbon environmental protection industry, but it does not prove that this industry will not destroy the existing environmental and geological resources. Therefore, it should pay attention to the resources and environment protection from the beginning, formulate the corresponding policy and management system, implement the existing laws and regulations, strengthen the propaganda and education of tourism workers and tourists, cherish and maintain the rare geological and tourism resources, and ensure the continuous development and utilization ofgeological tourism resources of the Datong Volcanic Cluster. 


\subsection{Find the Right Position and Strengthen Publicity}

There are many various tourist attractions in the surrounding areas of Datong, so how to stand out from the competition and attract more tourists is a realistic problem facing Datong Volcanic Cluster National Geopark.The positioning of Datong Volcanic Cluster National Geopark should take geological tourism and environmental climate as its selling points, combining Datong's geographical advantages of being close to Beijing and making full use of Datong's cool climate characteristics and gourmet to create the summer leisure trip to the volcano.

\section{Conclusion}

This paper, aiming to study the development and protection of geological resources in Datong Volcanic Cluster National Geopark, draws the following conclusions through consulting materials and multiple field visits: Datong Volcanic Cluster National Geopark has distinct resource features and high scientific research and ornamental value, but the development of relevant tourism is only in the stage of infrastructure construction and receives just little attention from the outside world. Meanwhile, the competition in its surrounding areas is fierce, with development opportunities and crises coexisting. If the manager of the park can properly handle the balance between resource development and protection, develop the park's regional advantages, seize opportunities, find it's positioning, and increase the publicity, the park will become a benchmark for tourism in Datong and its surrounding areas.

Acknowledge

2018 Youth Science Funds of Shan Xi Da Tong university(2018Q3)

\section{References}

1. J. Deng, X. Mo, P. Lin. J. May 12, 233-239 (1987)

2. Y. Li, J. Li, Y. Wu. J. Jun 32, 46-49 (2017)

3. H. Xue, W. Zhang. J. Dec 24, 189-194 (2010) 